This abstract is intended for (double click the selected box and then check):

Oral presentation

Poster presentation

Invited lecture

\title{
EFECT OF INORGANIC CONTENT ON THE PERFORMANCE OF ANTICORROSIVE HYBRID SOL-GEL COATED EN AW-6063 ALLOY
}

\author{
I. Rute Fontinha ${ }^{1 *} ;$ M. Manuela Salta ${ }^{2}$, M. Zheludkevich ${ }^{3}$, M.G.S Ferreira, \\ ${ }^{1}$ Laboratório Nacional de Engenharia Civil, Av. Brasil, 101, 1700-066 Lisboa, Portugal, rfontinha@lnec.pt \\ ${ }^{2}$ Laboratório Nacional de Engenharia Civil, Av. Brasil, 101, 1700-066 Lisboa,, Portugal \\ ${ }^{3}$ University of Aveiro, CICECO, Department of Ceramics and Glass Engineering, 3810-193 Aveiro, Portugal \\ ${ }^{4}$ Instituto Superior Técnico, ICEMS, DEQB, 1049-001 Lisboa, Portugal
}

The organic-inorganic hybrid sol-gel films have been reported as an effective anti-corrosion and environmentally friendly alternative to $\mathrm{Cr}(\mathrm{VI})$ pre-treatment for aluminium alloys. These hybrid materials, constituted by nanostructured polymer networks, interconnecting organic and inorganic materials, are of interest because the synergic effect on the mechanical and chemical properties achieved. The organic components impart flexibility, density and functional compatibility with organic coatings, while inorganic components impart hardness, resistance to abrasion and improve adhesion to the metal substrate.

The sol-gel process used to obtain these coatings, through a series of simultaneous hydrolysis and condensations reactions between alkoxide precursors, yields highly adherent, chemically inert films on metal substrates and allows the variation of the different synthesis parameters to achieve coatings with optimized properties. In this work, hybrid films were synthesized from glycidoxypropyltrimethoxysilane (GPTMS) and zirconium n-propoxide (TPOZ) precursors, using different amounts of TPOZ $(10 \%, 20 \%, 30 \%)$ and applied to EN AW-6063 alloy by dip-coating, aiming to achieve the best anticorrosive coating.

The corrosion behaviour of aluminium specimens coated with these films was evaluated by Electrochemical Impedance Spectroscopy (EIS) in $0.5 \mathrm{M} \mathrm{NaCl}$ solution for 63 days. The results obtained revealed that the hybrid films provided effective corrosion protection, exhibiting good barrier properties, however, it was found that $30 \%$ of TPOZ led to a marked decrease in the barrier properties with time. The hybrid films prepared were also characterized by Energy Dispersive Spectroscopy (EDS), Scanning Electron Microscopy (SEM), Infrared Spectroscopy and Thermogravimetric Analysis (TGA-DTG) in order to relate their morphology and chemical structure with the corrosion behaviour.

Keywords: Hybrid coating, sol-gel, corrosion, aluminium 